\title{
Oat fibre and chilli promote satiety synergistically
}

\author{
H. Gani ${ }^{1,2}$, J. Fearnley ${ }^{1}$, P. $\mathrm{Ho}^{1}$ and C. Orfila ${ }^{1}$ \\ ${ }^{1}$ School of Food Science and Nutrition, Faculty of Mathematics and Physical Sciences, University of Leeds, LS2 9JT \\ and ${ }^{2}$ Faculty of Bioresources and Food Industry, Universiti Sultan Zainal Abidin, 22200 Terengganu Malaysia.
}

According to the World Health Organization (WHO), obesity has become a global health problem. Approximately 2 billion adults were overweight and over 650 million of these were classed obese in $2016^{(1)}$. Ready access to energy-dense, highly palatable food contributes to an obesogenic environment ${ }^{(2)}$. The demand for food consumption is not just driven by a need for energy but also by the pleasure of eating the food itself ${ }^{(3)}$. In order to control obesity, foods that increase satiation and satiety may be beneficial to reduce food intake ${ }^{(4)}$. Noodles served in a spicy broth are the basis of many Asian dishes. Capsaicin, the major pungent substance in chilli peppers, and oat fibre have been shown to increase satiety ${ }^{(5,6)}$. This study aimed to test the hypothesis that oat fibre and chilli may interact to affect satiety in humans.

The satiety study was a randomised crossover design with 12 untrained volunteers (ethical reference number University of Leeds MEEC 16-040). The fasted subjects consumed a noodle soup breakfast meal (125 g cooked noodle in $200 \mathrm{ml}$ clear broth) with 3 different levels of fibre in the noddle $(0,10,20 \% \mathrm{w} / \mathrm{w}$ of oat fibre (BG28, Swedish Oat Fibre) in strong wheat flour) and 2 levels of chilli $(0$ and $1 \% \mathrm{w} / \mathrm{v})$ in the broth over 6 breakfast sessions. Satiety was measured immediately pre- and post- consumption of the noodle meal with a 7-category intensity scale (none to strongest imaginable), measuring five attributes (hunger, fullness, desire to eat more food, desire to eat the next meal and willingness to eat). Results were analysed using a linear mixed model repeated measures ANOVA and Cohen's d for effects size.

Table 1. Comparisons of the mean estimates for the difference after and before the meal between the control condition (no added fibre and no chilli) and different experimental conditions for hunger and fullness attributes

\begin{tabular}{|c|c|c|c|c|c|c|c|c|c|}
\hline \multirow[b]{2}{*}{ Fibre } & \multirow[b]{2}{*}{ Chilli } & \multicolumn{4}{|c|}{ Hunger } & \multicolumn{4}{|c|}{ Fullness } \\
\hline & & Diff & Effect size (d) & $p$-value & $95 \% \mathrm{CI}$ & Diff & Effect size (d) & $p$-value & $95 \% \mathrm{CI}$ \\
\hline None & Present & $-0 \cdot 17$ & -0.40 & $0 \cdot 35$ & {$[-1 \cdot 25,0 \cdot 46]$} & $-0 \cdot 42$ & -1.08 & $0 \cdot 02$ & {$[-1 \cdot 98,0 \cdot 17]$} \\
\hline $10 \%$ & None & 0.25 & 0.60 & $0 \cdot 17$ & {$[-0.27,1.46]$} & 0.67 & 1.72 & $<0.01$ & {$[0 \cdot 73,2 \cdot 72]$} \\
\hline $10 \%$ & Present & -0.08 & $-0 \cdot 20$ & 0.63 & {$[-1 \cdot 05,0 \cdot 65]$} & -0.08 & $-0 \cdot 22$ & 0.60 & {$[-1 \cdot 06,0 \cdot 63]$} \\
\hline $20 \%$ & None & $0 \cdot 50$ & $1 \cdot 19$ & $0 \cdot 01$ & {$[0 \cdot 27,2 \cdot 11]$} & $0 \cdot 33$ & 0.86 & 0.06 & {$[-0 \cdot 02,1 \cdot 75]$} \\
\hline $20 \%$ & Present & 0.83 & 1.99 & $<0.01$ & {$[0 \cdot 95,3 \cdot 02]$} & 0.67 & 1.72 & $<0.01$ & {$[0.73,2 \cdot 72]$} \\
\hline
\end{tabular}

Hunger levels for all conditions decreased and fullness levels increased significantly after meal consumption. The addition of chilli to the $20 \%$ fibre noodles had the most significant effect on hunger and fullness followed by $20 \%$ fibre noodle without chilli. Chilli had no effect on hunger and fullness at $10 \%$ fibre, but seem to reduce fullness at $0 \%$ fibre. In conclusion, fibre and chilli appear to affect satiety synergistically at higher fibre levels. Future work will focus on determining the optimal level of fibre and capsaicin that can contribute to higher satiety effect and to investigate effects over longer post-meal periods.

The authors wish to thank Swedish Oat Fiber (Naturex), Sweden, for providing oat fibre and funding from the Ministry of Higher Education, Government of Malaysia.

1. World Health Organization - Obesity and overweight. Factsheet No. 311. Available from: http://www.who.int/mediacentre/factsheets/fs311/en/ [Accessed $5^{\text {th }}$ March 2018]

2. Lake A \& Townshend T (2006) J R Soc Promot Health 126(6), 262-67.

3. Lowe MR \& Butryn ML (2007) Physiol Behav 91(4), 432-39.

4. Hetherington MM, Cunningham K, et al. (2013) Nutr Res Rev 26(1), 22-38.

5. Van Avesaat M, Troost FJ, et al. (2016) Am J Clin Nutr 103, 305-13.

6. Rebello CJ, O’Neil CE \& Greenway FL (2016) Nutr Rev 74(2), 131-47. 